\title{
Analisis Miskonsepsi Terhadap Materi Rangkaian Listrik Searah (DC) pada Siswa SMK Negeri Kota Kendari Menggunakan Four-Tier Diagnostic Test
}

\author{
Agus Trisnawati ${ }^{1{ }^{*}}$, Erniwati $^{2)}$, Rosliana Eso ${ }^{2)}$, Mustari $^{\text {3) }}$ \\ 1)*Jurusan Pendidikan Fisika, FKIP Universitas Halu Oleo, Indonesia \\ ${ }^{2)}$ Jurusan Pendidikan Fisika, FKIP Universitas Halu Oleo, Indonesia \\ ${ }^{3)}$ SMP Negeri 52 Konawe Selatan, Indonesia \\ *Korespondensi Penulis, Email: agustrisnawati3@gmail.com
}

\begin{abstract}
Abstrak: Penelitian ini bertujuan untuk menganalisis miskonsepsi materi rangkaian listrik arus searah (DC) pada siswa SMK Negeri Kota Kendari menggunakan four-tier diagnostic test. Populasi penelitian ini adalah seluruh siswa kelas XI SMK Negeri Kota Kendari yang telah mempelajari fisika. Pengambilan sampel menggunakan teknik purposive sampling dengan pertimbangan mengambil sekolah yang memiliki kejuruan yang sama sehingga di peroleh 4 kelas dari jurusan Teknik komputer dan jaringan yang berjumlah 110 orang. Pengumpulan data dilakukan dengan memberikan instrumen tes brupa soal four-tier diagnostic test yang berjumlah 15 nomor, yang diadopsi dari soal Tami Beniarti tahun 2018 dan wawancara. Data dianalisis menggunakan analisis deskriptif kualitatif sehingga diperoleh persentase paham konsep, miskonsepsi, paham sebagian, tidak paham konsep dan tidak dapat dikodekan pada siswa sehingga diperoleh kesimpulan : (1) persentase rata-rata pemahaman konsep sebesar $12,8 \%$, miskonsepsi sebesar $24,1 \%$, tidak paham konsep sebesar 23,4\%, paham sebagian sebesar 37,5\%, dan tidak dapat dikodekan sebesar 2,2\%, (2) Miskonsepsi siswa tiap sub-konsep secara berturut-turut adalah arus listrik dan beda potensial $(34,24 \%)$, hambatan dan rangkaian hambatan listrik $(23,94 \%)$, analisis rangkaian sederhana $(17,88 \%)$, hukum Ohm $(21,82 \%)$, dan hukum Kirchoff (22,73\%), (3) Persentase miskonsepsi pada siswa di masing-masing SMK yaitu pada SMKN 1 Kendari persentase miskonsepsi sebesar 18,0\%, untuk SMKN 3 Kendari persentase miskonsepsi sebesar 19,7\%, untuk SMKN 4 Kendari persentase miskonsepsi sebesar 29,9\%, sedangkan untuk SMKN 5 Kendari persentase miskonsepsi sebesar $29,3 \%$. Secara keseluruhan persentase yang didapatkan untuk masing-masing sekolah adalah berkategori rendah.
\end{abstract}

Kata Kunci: Miskonsepsi; Four-Tier Test; Rangkaian Listrik Searah

\begin{abstract}
This study aims to analyze the misconceptions of unidirectional electric circuit material in elementary school students of the city of Kendari using a four-tier test. Sampling uses a purposive sampling technique with the consideration of taking schools that have the same vocational training so that they get 4 classes from the Department of Computer and Network Engineering totaling 110 people. The population of this research is all students of SMK Negeri Kendari City. Data collection was carried out by providing a test instrument in the form of four-tier diagnostic test questions totaling 15 numbers, which were adopted from the 2018 Tami Beniarti questions and interviews. Data were analyzed using qualitative descriptive analysis to obtain a percentage of concept understanding, misconception, partial understanding, not understanding the concept and cannot be coded to students so that conclusions are obtained: (1) the average percentage of concept understanding is $12.8 \%$, misconceptions are $24.1 \%$, do not understand the concept of $23.4 \%$, understand partially by 37.5\%, and cannot be coded as much as 2.2\%, (2) Students' misconceptions of each sub-concept are successively electric current and potential difference (34), 24\%), electrical resistance and circuit resistance (23.94\%), simple circuit analysis (17.88\%), Ohm's law (21.82\%), and Kirchoff's law (22.73\%), (3) percentage of misconceptions among students in each vocational high school namely at SMKN 1 Kendari the percentage of misconceptions was $18.0 \%$, for SMKN 3 Kendari the percentage of misconceptions was 19.7\%, for SMKN 4 Kendari the percentage of misconceptions was 29.9\%, whereas for SMKN 5 Kendari the percentage of misconceptions of 29.3\%. Overall the percentage obtained for each school is of low category.
\end{abstract}

Keywords: Misconception; Four-Tier Test; Unidirectional Electric Circuit 


\section{PENDAHULUAN}

Fisika merupakan ilmu yang mempelajari tentang alam beserta gejala-gejala yang terjadi di sekitarnya yang melalui serangkaian proses ilmiah dan hasilnya terwujud sebagai produk ilmiah yang tersusun atas konsep, prinsip, dan teori. Fisika berkaitan erat dengan alam, sehingga ketika mempelajari fisika harus mampu memahami konsep dari suatu materi fisika. Pemahaman sebuah konsep fisika merupakan suatu hal yang sangat penting dalam mempelajari dan memahami interaksi atau fenomena yang ada di alam. Setiap konsep tidak berdiri sendiri melainkan adanya keterkaitan antara konsep yang satu dengan konsep yang lain.

Mosik (2010) menyatakan bahwa sebelum mempelajari fisika, siswa hadir di kelas tidak dalam keadaan kepala kosong, dalam struktur kognitif siswa telah terbentuk sebagai prakonsepsi mengenai peristiwa dan pengertian tentang konsep-konsep fisika. Akan tetapi konsepsi awal yang terbentuk tersebut belum tentu benar. Dalam hal ini, apabila konsepkonsep baru langsung dimasukkan dalam struktur kognitif siswa maka akan terjadi pencampuran konsep lama (konsep yang belum tentu benar) dan konsep baru yang belum tentu dipahami dengan baik oleh siswa. Akibat pencampuran konsep tersebut menjadikan penafsiran yang salah (Tayubi, 2005). Penafsiran siswa mengenai suatu konsep yang berbeda dengan ilmuwan fisika ini disebut dengan miskonsepsi (Fariyani, 2015). Miskonsepsi adalah kesalahan penafsiran konsep yang tidak sesuai dengan apa yang dimaksudkan oleh para ilmuan (Suparno, 2013). Miskonsepsi terjadi pada berbagai bidang keilmuan, salah satunya adalah fisika. Banyaknya miskonsepsi yang dialami siswa dalam mempelajari fisika karena banyak materi yang abstrak sehingga siswa sulit memahami konsep yang benar. Salah satu materi fisika yang bersifat abstrak adalah materi listrik. Wandersee, dalam Zulvita (2017), mengungkapkan bahwa miskonsepsi tentang listrik menempati urutan kedua setelah mekanika. Sejumlah penelitian telah berhasil menemukan bentuk miskonsepsi tentang listrik, misalnya pada rangkaian listrik.

Hasil penelitian yang dilakukan oleh McDermot dan Shaffer (1992) dalam Pamungkas (2016) menyatakan bahwa siswa menganggap arus yang dekat dengan kutub positif lebih besar dari pada dekat kutub negatif. Hasil penelitian yang dilakukan oleh Yunita (2017) juga menyatakan bahwa mahasiswa yang mengalami miskonsepsi pada konsep alat ukur listrik sebesar 54,76\%, konsep hukum Ohm sebesar 61,9\%, konsep hukum Kirchoff sebesar $42,38 \%$ dan untuk konsep rangkaian seri dan paralel sebesar $41,67 \%$.
Berdasarkan berbagai penelitian tersebut dapat disimpulkan bahwa miskonsepsi pada siswa/mahasiswa masih terjadi pada materi rangkaian listrik.

Berdasarkan hasil wawancara yang diperoleh dari beberapa guru di SMK Negeri kota Kendari, mereka mengatakan bahwa banyak peserta didik yang menganggap bahwa fisika itu sulit sehingga ketika belajar fisika mereka cenderung malas. Selain itu, nilai ulangan fisika rata-rata di bawah KKM. Beberapa peserta didik juga masih kesulitan dalam menghubungkan keterkaitan antara konsep suatu materi maupun saat dihadapkan dengan pertanyaan atau soal mengenai konsep fisika yang bisa menyebabkan adanya miskonsepsi. Dari hasil wawancara tersebut, didapatkan kaitannya dengan miskonsepsi adalah terjadi dampak yang ditimbulkan dari adanya miskonsepsi yaitu hasil belajar siswa kurang berhasil yang ditandai dengan nilai ulangan siswa yang di bawah KKM, sehingga perlu diteliti apakah siswa memang tidak memahami konsep atau mengalami miskonsepsi. Seperti yang diungkapkan oleh Beniarti (2018), bahwa siswa yang telah memahami konsep dapat terukur dari hasil belajar yang baik.

Identifikasi miskonsepsi siswa sangat penting dilakukan untuk proses pembelajaran siswa kedepannya. Apabila miskonsepsi tetap dibiarkan maka akan mempengaruhi proses belajar siswa dan mereka akan kesulitan untuk memahami konsepkonsep selanjutnya. Sehingga konsepsi yang dimiliki siswa menjadi tidak bermakna karena tidak dapat dihubungkan dengan konsep sebelumnya.

Salah satu cara yang digunakan untuk mengetahui miskonsepsi siswa adalah dengan menggunakan tes diagnostik bentuk four-tier test (Zaleha, 2017). Menurut Zulfikar (2017) instrumen tes diagnostik bentuk four-tier test berpotensi untuk mendiagnosis level konsepsi siswa pada suatu konsep fisika.

Berdasarkan beberapa penjelasan permasalahan tentang miskonsepsi yang terjadi dalam bidang fisika, maka perlu dilakukan penelitian tentang miskonsepsi siswa pada materi Rangkaian Listrik Searah (DC) di Sekolah Menengah Kejuruan dengan tujuan untuk menganalisis miskonsepsi materi rangkaian listrik searah (DC) pada siswa SMK Negeri Kota Kendari Menggunakan Four-Tier Diagnostic Test.

\section{METODE}

Jenis penelitian ini adalah penelitian deskriptif kualitatif. Menurut Arikunto, penelitian deskriptif adalah prosedur pemecahan masalah yang diselidiki dengan menggambarkan atau melukiskan keadaan 
suatu objek penelitian. Bog dan taylor dalam Andi prastowo (2011), menjelaskan bahwa penelitian kualitatif adalah salah satu prosedur penelitian yang menghasilkan data deskriptif kualitatif berupa katakata tertulis atau lisan dari orang-orang dan perilaku yang diamati.

Penelitian ini dilaksanakan pada bulan September 2019 di SMK Negeri Kota Kendari. Populasi dari penelitian ini adalah siswa yang telah mempelajari materi rangkaian listrik searah yaitu seluruh kelas XI SMK yang belajar fisika. Pengambilan sampel menggunakan teknik purposive sampling.

Pengumpulan data miskonsepsi dilakukan dengan memberikan tes miskonsepsi tentang rangkaian listrik searah (DC) berupa soal four-tier diagnostik test yang di adopsi dari Tami Beniarti (2018) dan wawancara.

Prosedur penelitian ini adalah sebagai berikut.

a. Menyediakan instrumen yang akan digunakan dalam penelitian (instrumen berupa Four-Tier Test).

b. Melakukan validasi instrumen oleh beberapa ahli (Dosen jurusan Pendidikan Fisika dan Dosen MIPA Universitas Halu Oleo).

c. Memberikan soal tes diagnostik four tier test kepada siswa, sesuai dengan kelas sampel yang ditentukan. d. Memeriksa hasil jawaban tes diagnostik four tier test.

e. Mendata jawaban siswa di setiap butir soal ke dalam kategori paham konsep, paham sebagian, tidak paham konsep, dan miskonsepsi.

f. Melakukan analisis data dari data yang telah diperoleh. Peneliti mendeskripsikan miskonsepsi yang dialami siswa pada pokok bahasan Rangkaian listrik searah (DC) yang kemudian digambarkan dalam bentuk tabel dan diagram.

g. Membuat kesimpulan berdasarkan hasil analisis data yang diperoleh. Tahap ini merupakan tahap dimana peneliti akan melakukan penarikan kesimpulan terhadap hasil analisis data dengan mendeskripsikan miskonsepsi yang dialami siswa.

Teknik analisis data yang dilakukan pada penelitian ini adalah sebagai berikut.

Mendata jawaban siswa disetiap butir soal ke dalam 5 kategori yaitu paham konsep, miskonsepsi, tidak paham konsep, paham sebagian, dan tidak dapat dikodekan yang diadopsi dari $\operatorname{Amin}(2016)$, sesuai dengan kriteria yang terdapat pada tabel 1 berikut.

Tabel 1. Kategori Jawaban Four-Tier Test

\begin{tabular}{cccccc}
\hline No. & Kategori & Opsi & Tingkat Keyakinan & Alasan & Tingkat Keyakinan \\
\hline 1 & Miskonsepsi(M) & Salah & Yakin & Salah & Yakin \\
\hline 2 & & Salah & Yakin & Salah & Tidak Yakin \\
3 & Tidak Paham Konsep (TPK) & Salah & Tidak Yakin & Salah & Yakin \\
4 & & Salah & Tidak Yakin & Salah & Tidak Yakin \\
\hline 5 & Paham Konsep (PK) & Benar & Yakin & Benar & Yakin \\
\hline 6 & & Benar & Yakin & Benar & Tidak Yakin \\
7 & & Benar & Tidak Yakin & Benar & Yakin \\
8 & & Benar & Tidak Yakin & Benar & Tidak Yakin \\
9 & & Benar & Yakin & Salah & Yakin \\
10 & & Benar & Yakin & Salah & Tidak Yakin \\
11 & Paham Sebagian (PS) & Benar & Tidak Yakin & Salah & Yakin \\
12 & & Benar & Tidak Yakin & Salah & Tidak Yakin \\
13 & & Salah & Yakin & Benar & Yakin \\
14 & & Salah & Yakin & Benar & Tidak Yakin \\
15 & & Salah & Tidak Yakin & Benar & Yakin \\
16 & & Salah & Tidak Yakin & Benar & Yakin \\
\hline 17 & Tidak Dapat Dikodekan(TKD) & \multicolumn{4}{c}{ Apabila salah satu, dua, tiga atau semuanya tidak di isi } \\
\hline
\end{tabular}

Kemudian menghitung persentase pemahaman siswa menggunakan persamaan yang dilakukan oleh
Sudijono (2010) dalam Sheftyawan (2018) sebagai berikut. 


$$
P=\frac{f}{n} x 100 \%
$$

Keterangan:

$P=$ angka persentase kelompok

$f=$ jumlah siswa tiap kelompok

$n=$ jumlah individu (jumlah seluruh siswa yang

menjadi subjek penelitian)
HASIL DAN PEMBAHASAN

\section{Persentase Jawaban Four-Tier Diagnostict Test secara Keseluruhan}

Persentase jawaban Four-Tier Diagnostict Test siswa SMK Negeri Kota Kendari dapat dilihat pada tabel 2 berikut.

Tabel 2 Persentase Kategori Jawaban Four-tier Test dari 110 siswa di SMK Negeri kota Kendari

\begin{tabular}{cccccc}
\hline & \multicolumn{5}{c}{ Persentase kategori Jawaban Siswa (\%) } \\
\cline { 2 - 6 } Butir Soal & Paham Konsep & Miskonsepsi & $\begin{array}{c}\text { Tidak Paham } \\
\text { Konsep }\end{array}$ & $\begin{array}{c}\text { Paham } \\
\text { Sebagian }\end{array}$ & $\begin{array}{c}\text { Tidak Dapat } \\
\text { Dikodekan }\end{array}$ \\
\hline 1 & 6,4 & 38,2 & 17,3 & 36,4 & 1,8 \\
2 & 24,5 & 20 & 19,1 & 34,5 & 1,8 \\
3 & 6,4 & 44,5 & 24,5 & 22,7 & 1,8 \\
4 & 17,3 & 22,7 & 18,2 & 39,1 & 2,7 \\
5 & 14,5 & 20,9 & 14,5 & 50 & 0 \\
6 & 17,3 & 28,2 & 29,1 & 24,5 & 0,9 \\
7 & 7,3 & 19,1 & 22,7 & 49,1 & 1,8 \\
8 & 20,9 & 10,9 & 24,5 & 41,8 & 1,8 \\
9 & 10,9 & 23,6 & 16,4 & 45,5 & 3,6 \\
10 & 16,4 & 23,6 & 25,5 & 30,9 & 3,6 \\
11 & 7,3 & 22,7 & 29,1 & 37,3 & 3,6 \\
12 & 20,9 & 19,1 & 19,1 & 38,2 & 2,7 \\
13 & 11,8 & 21,8 & 34,5 & 30 & 1,8 \\
14 & 9,1 & 18,2 & 30,9 & 39,1 & 2,7 \\
15 & 1,8 & 28,2 & 25,5 & 42,7 & 1,8 \\
\hline Rata-Rata & 12,8 & 24,1 & 23,4 & 37,5 & 2,2
\end{tabular}

Berdasarkan data hasil tes diagnostik dengan soal Four-tier Test pada tabel 1 diketahui bahwa dari 15 nomor soal yang diberikan kepada 110 siswa, sebesar $24,1 \%$ peserta didik masih mengalami miskonsepi pada konsep rangkaian listrik searah, nilai tersebut masuk dalam kategori miskonsepsi rendah. Setelah tes diagnostik four-tier test dilakukan diketahui bahwa tingkat pemahaman konsep siswa di SMK Negeri kota Kendari terhadap materi rangkaian listrik searah secara umum masih rendah. Terlihat dari persentase rata-rata tiap kategori pada tabel 1, dimana kategori paham konsep memiliki persentase yang paling terendah dibandingkan kategori lainnya. Namun kategori miskonsepsi terlihat lebih sedikit dibandingkan dengan siswa yang paham sebagian tetapi lebih banyak dari siswa yang paham konsep dan tidak dapat dikodekan namun tidak jauh berbeda dengan yang tidak paham konsep Rendahnya persentase paham konsep disebabkan oleh siswa yang telah lupa akan materi rangkaian listrik tersebut. Sehingga mereka cenderung asal menjawab, ditandai dengan cepatnya waktu penyelesaian pengerjaan soal yang dialami oleh sebagian siswa dan tingginya persentase paham sebagian dimana kategori paham sebagian juga memiliki opsi yang cukup banyak sehingga ketika siswa sama sekali tidak tahu materi soal lalu asal memilih option. Hal ini yang menyebabkan tingginya persentase paham sebagian. Sebagaimana menurut pendapat Gagne dalam sarinah (2018) yang mengungkapkan bahwa informasi yang ditangkap panca indera masuk kedalam memori jangka pendek yang memiliki kapasitas terbatas, dimana informasi hanya mampu dipertahankan sekitar 30 detik.

2. Data Persentase Paham Konsep, Miskonsepsi, Tidak Paham Konsep, Paham Sebagian dan Tidak dapat Dikodekan Siswa pada Tiap SubKonsep 
Persentase Paham Konsep, Miskonsepsi, Tidak Dikodekan Siswa pada Tiap Sub-Konsep dapat dilihat Paham Konsep, Paham Sebagian dan Tidak dapat pada Gambar 1.

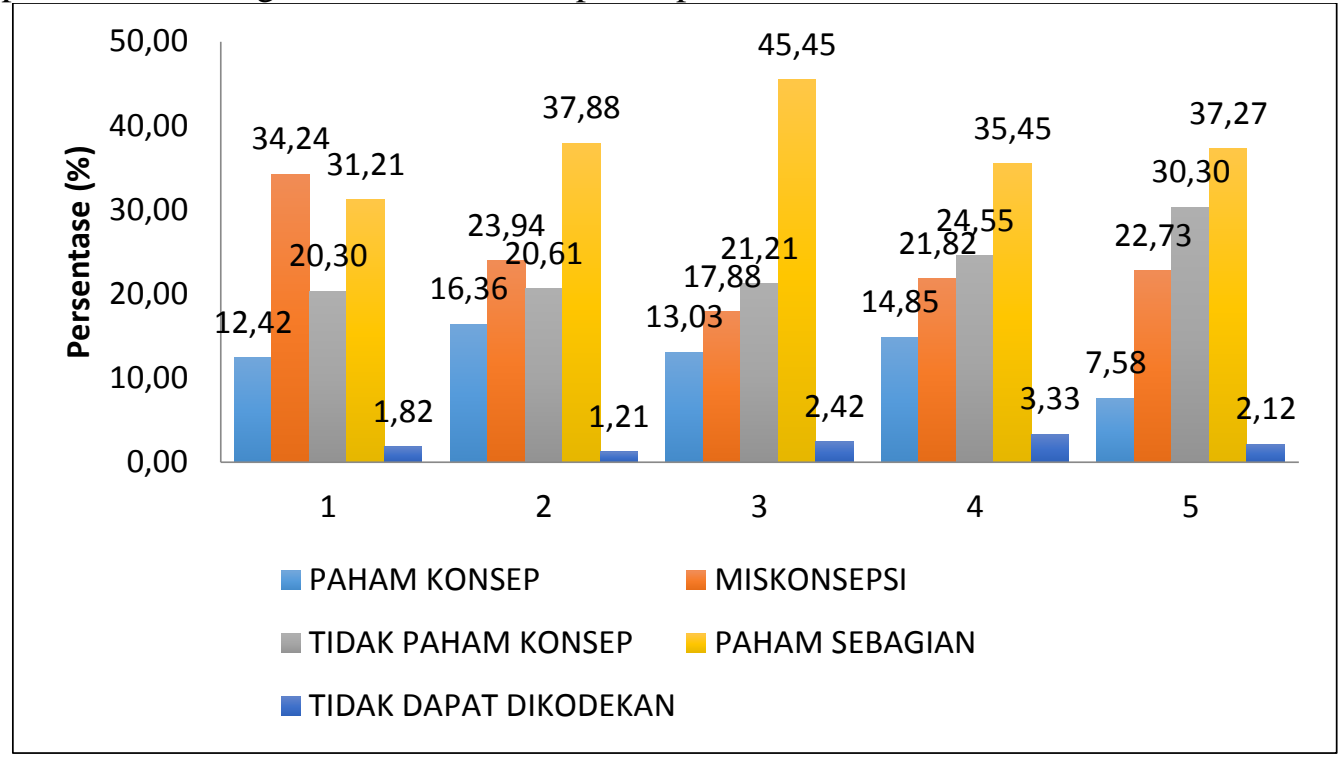

Gambar 1 Persentase Tingkat Miskonsepsi Peserta Didik Sub-Konsep:(1)Arus Listrik dan Beda Potensial, (2) Hambatan Listrik, (3) Analisis Rangkaian Sederhana,(4) Hukum Ohm, (5) Hukum Kirchoff

Berdasarkan gambar 1, terlihat bahwa miskonsepsi tertinggi ada pada sub konsep yang pertama yaitu sub konsep arus dan beda potensial yaitu sebesar 34,24\%., sedangkan miskonsepsi dengan persentase terendah terjadi pada konsep analisis rangkaian sederhana sebesar $17,88 \%$. Hal ini terjadi karena siswa kurang memahami maksud soal yang ada pada sub konsep arus dan beda potensial. Hal yang sama juga didapatkan dalam penelitian Beniarti (2018) bahwa miskonsepsi yang memiliki persentase tertinggi terdapat pada sub-konsep arus listrik dan beda potensial.

1. Miskonsepsi Siswa pada Sub-Konsep Arus Listrik dan Beda Potensial

Miskonsepsi yang terungkap paling tinggi untuk sub konsep ini terdapat pada soal nomor 3 yaitu sebesar 44,5\%, dimana siswa menganggap bahwa beda potensial pada rangkaian paralel akan bertambah sehingga nyala lampu akan lebih terang karena dua baterai lebih besar tegangannya dibandingkan satu baterai. Jawaban yang benar adalah beda potensial akan tetap meskipun baterai disusun secara paralel karena nilai beda potensial tidak berpengaruh. Hal ini disebabkan karena siswa belum mampu memahami besar nilai beda potensial pada rangkaian paralel. Hal yang sama senada dengan Ismiara (2015), menyatakan bahwa sekitar 50\% siswa beranggapan bahwa besar beda potensial pada rangkaian tertutup dapat bernilai nol.
2. Miskonsepsi Siswa pada Sub-Konsep Rangkaian Hambatan listrik

Miskonsepsi yang terungkap paling tinggi untuk sub konsep ini terdapat pada soal nomor 6 yaitu sebesar $28,2 \%$, dimana siswa menganggap bahwa jika salah satu lampu pada rangkaian paralel dicabut, maka lampu lainnya akan menyala lebih terang. Jawaban yang benar adalah nyala lampu tidak berubah. Hal ini terjadi karena siswa tidak memahami prinsip kerja dari rangkaian paralel. Hal yang sama senada dengan Beniarti (2018), menyatakan bahwa 9,7\% siswa mengalami miskonsepsi dengan menganggap konsep yang sama yaitu jika salah satu lampu pada rangkaian paralel dilepas, maka lampu lainnya akan menyala lebih terang.

3. Miskonsepsi Siswa pada Sub-Konsep Analisis Rangkaian Sederhana

Miskonsepsi yang terungkap paling tinggi untuk sub konsep ini terdapat pada soal nomor 9 yaitu sebesar $23,6 \%$, dimana siswa menganggap bahwa tidak ada lampu yang menyala ketika saklar terbuka. Hal ini senada dengan Beniarti (2018), sebanyak 1,94\% siswa mengalami miskonsepsi dan menganggap lampu yang tersusun dalam satu rangkaian dan saklar terbuka maka semua lampu tidak ada yang menyala karena tidak ada arus yang mengalir. Padahal kenyataannya apabila saklar terbuka saat disusun secara paralel, maka semua lampu akan tetap menyala dan hanya lampu yang berdekatan dengan saklar terbuka yang tidak menyala. 4. Miskonsepsi Siswa pada Sub-Konsep Hukum Ohm 
Miskonsepsi yang terungkap paling tinggi untuk sub konsep ini terdapat pada soal nomor 10 yaitu sebesar 23,6\%, dimana siswa menganggap arus mengalir dari kutub negatif ke kutub positif, sehingga arus yang dekat dengan kutub negatif lebih besar dari arus yang dekat dengan kutub positif. Hal yang sama senada dengan Ismiara (2015), $81 \%$ siswa menganggap arus listrik adalah muatan positif yang bergerak.

5. Miskonsepsi Siswa pada Sub-Konsep Hukum

Kirchoff

Miskonsepsi yang terungkap paling tinggi untuk sub konsep ini terdapat pada soal nomor 15 yaitu sebesar 28,2\%, dimana siswa menganggap bahwa sumber arus yang mengalir pada suatu rangkaian tertutup sama dengan hambatannya. Hal yang sama senada dengan Rohmah (2017), menyatakan bahwa $43,9 \%$ siswa mengalami miskonsepsi tentang hukum kirchoff.

\section{Persentase Paham Konsep, Miskonsepsi, Tidak Paham Konsep, Paham Sebagian dan Tidak dapat Dikodekan pada Siswa di SMK Negeri Kota Kendari}

Persentase SMK Negeri Kota Kendari untuk kategori paham konsep, miskonsepsi, tidak paham konsep, paham sebagian dan tidak dapat di kodekan dapat dilihat pada gambar 2 berikut.

\section{Persentase Kategori Jawaban Four-Tier Test SMK Negeri Kota Kendari}

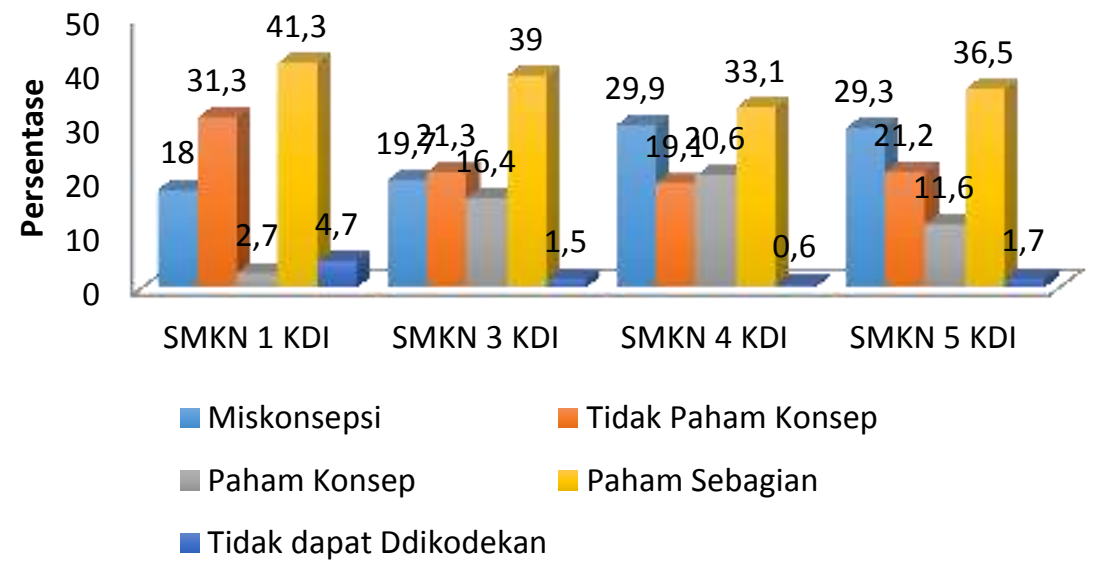

Gambar 2. Persentase Paham Konsep, Miskonsepsi, Tidak Paham Konsep, Paham Sebagian dan Tidak dapat Dikodekan Siswa di tiap SMK Negeri Kota Kendari

Berdasarkan gambar 2 terlihat persentase tingkat pemahaman konsep di empat SMK Negeri Kota Kendari, menunjukkan bahwa SMK Negeri 1 Kendari yang memiliki tingkat persentase paham konsep terendah. Hal ini disebabkan karena proses pembelajaran fisika waktu di kelas $\mathrm{X}$ sangat jarang dilakukan, guru mata pelajaran fisika masuk kurang lebih dua kali pertemuan dalam satu semester, sehingga mereka kurang mampu memahami berbagai konsep-konsep dalam fisika. Sedangkan untuk persentase tertingginya adalah SMK Negeri 4 Kendari. Siswa yang mengalami miskonsepsi dan tidak paham konsep, dalam memahami suatu konsep fisika hampir tidak begitu berbeda, karna perbedaan pemahaman konsepnya sangat tipis. Selain itu, dapat dilihat bahwa miskonsepsi terbesar ada di SMK Negeri 4 dan 5
Kendari sebesar masing-masing 29,9\% dan 29,3\%, hal ini dikarenakan dalam pembelajaran siswa tidak melakukan eksperimen, proses pembelajaran dilaksanakan secara diskusi membagi kelompok. Namun jika dibandingkan dengan siswa SMK Negeri 1 Kendari, mereka mendapatkan persentase miskonsepsi yang lebih kecil karena mereka menjawab soal dengan tidak serius, di tandai dengan cepatnya waktu pengerjaan soal yang mereka lakukan bila dibandingkan dengan sekolah lain. Sehingga hal itu bisa saja merupakan suatu kebetulan karena hampir seluruhnya asal menjawab. Begitu pula dengan pemahaman konsep dan paham konsep sebagian, siswa yang mengalami dua kategori ini tidak begitu berbeda dalam memahami sebuah konsep. Adanya persentase tidak dapat dikodekan pada masing-masing sekolah. 
Hal ini menunjukkan ketidakseriusan dalam menjawab soal.

Berdasarkan wawancara yang telah dilakukan kepada beberapa orang siswa yang mengalami miskonsepsi, dapat diketahui bahwa miskonsepsi terjadi salah satunya disebabkan oleh siswa itu sendiri. Dimana peserta didik kurang memiliki minat akan pembelajaran fisika sehingga mereka cenderung tidak memperhatikan ketika belajar fisika dalam kelas. Seperti yang diungkapkan oleh Ipek dalam Sarinah (2018), miskonsepsi juga bisa disebabkan oleh minat yang kurang dalam belajar fisika.

\section{KESIMPULAN}

Berdasarkan hasil penelitian analisis miskonsepsi tentang rangkaian listrik searah (DC) Pada siswa SMK Negeri Kota Kendari menggunakan Four-Tier Diagnostic Test, maka dapat disimpulkan bahwa persentase pemahaman konsep, miskonsepsi, tidak paham konsep, paham sebagian, dan tidak dapat dikodekan yang terjadi pada siswa secara berturut-turut persentasenya adalah $12,8 \%, 24,1 \%, 23,4 \% 37,5 \%$, dan $2,2 \%$.

\section{SARAN}

Berdasarkan kesimpulan penemuan dalam penelitian ini maka dapat disarankan bahwa:

1. Untuk guru, dapat digunakan sebagai bahan informasi agar dilakukan upaya untuk mengurangi miskonsepsi yang terjadi pada siswa dan memilih metode pembelajaran yang lebih baik agar siswa mampu mengingat materi yang di berikan dengan jangka waktu yang lama.

2. Untuk peneliti selanjutnya, sebaiknya penelitian dilakukan setelah siswa baru saja mempelajari materi rangkaian listrik searah agar mereka tidak lupa akan materi tersebut ketika menjawab tes yang diberikan.

\section{DAFTAR PUSTAKA}

Agustin, RD, Harijanto, A, Prastowo, SHB 2018. Identifikasi Miskonsepsi Siswa Pada Materi Rangkaian Arus Bolak-Balik Meguunakan FourTier Test di SMA, Seminar Nasional Pendidikan Fisika. Vol. 3. No. 2, hh. 2327-5817.

Amin, N., Wiendartun, dan Samsuddin, A 2016. Analisis Instrumen Tes Diagnostik DynamicFluid Conceptual Change Invertory (DFCCI) Bentuk Four-Tier Test Pada Beberapa SMA di Bandung Raya. PROSIDING SNIPS. Vol. 6. No. 2, hh. 602-978.
Andi, P 2011, Metode Penelitian Kualitatif dalam Perspektif Rancangan Penelitian, Ar-Ruzz Media, Depok.

Arikunto, S 2006, Prosedur Penelitian: Suatu Pendekatan Praktek, Rineka Cipta, Jakarta.

Beniarti, T, Prihandono, T, Supeno 2018. Analisis Miskonsepsi Siswa SMK Pada Pokok Bahasan Rangkaian Listrik. Seminar Nasional Pendidikan Fisika. Vol. 3. No. 2, hh.. 2527-5917.

Fariyani, Q, Rusilowati, A, dan Sugianto 2015. Pengembangan Four-Tier Diagnostic Test Untuk Mengungkap Miskonsepsi Fisika Siswa SMA Kelas X. Universitas Negeri semarang: Semarang.

Fitriah, L 2017. Diagnosis Miskonsepsi Siswa pada Materi Kalor dengan Menggunakan Three-Tier Essay dan Open-Ended Test ITEMS', Antasari Banjarmasin. Vol. 2 No. 2.

Hamdani 2013. Deskripsi Miskonsepsi Siswa Tentang Konsep-Konsep dalam Rangkaian Listrik', Jurnal Pendidikan Matematika dan Ipa . Vol. 4 No. 1, hh..1-12.

Ismail, II, Samsudin, A, Suhendi, E, dan Kaniawati, I 2015, Diagnostik Miskonsepsi Melalui Listrik Dinamis Four Tier Test, Prosiding Simposium Nasional Inovasi dan Pembelajaran Sains, Vol. 3. No. 1 hh.. 381-384, dilihat 19 Juli 2019.

Ma'rifatun, D, Martini, KS, Utomo, SB 2014. Pengaruh Model Pembelajaran POE Menggunakan Metode Eksperimen Terhadap Prestasi Belajar Siswa. Jurnal Pendidikan Kimia, Vol. 3. No. 3, hh.. 11-16.

Rohmah, RN, Lesmono, AD, Harijanto, A 2017. Identifikasi Miskonsepsi Siswa Pada Pokok Bahasan Rangkaian Arus Searah di Kelas XII MAN 1 Jember', Seminar Nasional Pendidikan Fisika, Vol. 2. No.1. hh.. 2527-5917.

Rusilowati, A 2015. Pengembangan Tes Diagnostik Sebagai Alat Evaluasi Kesulitan Belajar Fisika', Jurnal Pendidikan. Vol. 6. No. 1. hh 2302-7827.

Santrock, John, W 2008.Psikologi Pendidikan, Kencana: Jakarta. 
Sarinah, S 2018. Analisis Miskonsepsi Tentang Kalor dan Perpindahannya Bagi Siswa SMPN 2 Tiworo Selatan. Jurnal Pendidikan Fisika.

Sheftyawan, WB, Prihandono, T, dan Lesmono, AD 2018. Identifikasi Miskonsepsi Siswa Menggunakan Four-Tier Diagnostic Test Pada Materi Optik Geometri. Jurnal Pembelajaran Fisika, Vol. 7. No. 2. hh. 147-153.

Sholihat, FN, Samsudin, A, dan Nugraha, MG 2017. Identifikasi Miskonsepsi dan Penyebab Miskonsepsi Siswa Menggunakan Four-Tier Diagnostic Test pada Sub-Materi Fluida Dinamik: Azas Kontinuitas. Jurnal penelitian \& Pengembangan Fisika, Vol. 3. No. 2. Hh.. 24611433.

Suwarna, IP 2013, Analisis Miskonsepsi Siswa SMA Kelas X Pada Mata Pelajaran Fisika Melalui CRI (Certainly of Response Index) Termodifikasi, UIN Syarif Hidayatullah, Jakarta.

Tayubi, YR 2005, Identifikasi Miskonsepsi pada Konsep-konsep Fisika Menggunakan Certainly of response index(CRI),Jurnal Universitas Pendidikan Indonesia, Vol. 3. No. 2. hh..4-9.

Trianto 2010, Mendesain Model Pembelajaran Inovatif Progresif, Kencana Prenada Media Group, Jakarta.

Zaleha, Samsuddin, A dan Nugraha, MG 2017, 'Pengembangan Instrumen Tes Diagnostik VCCI Bdntuk Four-Tier Test pada Konsep Getaran', Jurnal Pendidikan dan Keilmuan, Vol. 3. No. 1. hh.. 36-42.

Zulvita, R, Hamlin, A, dan Elisa 2017, 'Identifikasi dan Remediasi Miskonsepsi Konsep Hukum Newton dengan Menggunakan Metode Eksperimen di MAN Darussalam', Jurnal Pendidikan Fisika, Vol. 2. No. 1. hh. 789-797. 